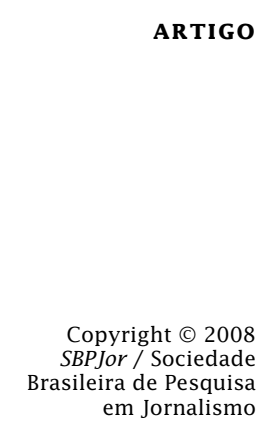

\title{
IMAGENS NO CALOR DA HORA OU A FENIX RENASCIDA DA IMAGEM DOCUMENTAL
}

\begin{abstract}
RESUMO Apesar da freqüente discussão, tanto nos meios acadêmicos quanto nos midiáticos, envolvendo a crise da imagem documental, na esteira da propalada crise da cultura documental como um todo, não há como negar a proliferação de imagens e o incremento de uma produção assumida com esse propósito no universo das relações comunicacionais, seja ele impresso ou digital. Se, no domínio da arte, a ação hegemônica contemporânea consiste na desestabilização figurativa das imagens, do lado das mídias de produção massiva, afirma-se a sua estabilização como condição fundante do ato de documentar. Este trabalho não visa a abordar as várias concepções de documental, porque parte do pressuposto de que esse aspecto se apresenta como resultado de estratégias figurativo-enunciativas de "fazer crer", responsáveis por múltiplos regimes de sentido. De suas escolhas e agenciamentos decorrem modalidades interacionais amparadas na mediatez ou imediatez dos processos compreensivos, num sistema de valores condicionantes do ato comunicativo que coloca em evidência as funções prática, cognitiva, afetiva ou fiduciária (calcada em regimes de crença) das mediações simbólicas. A questão mais geral que norteia o presente texto é indagar como as diferentes mídias, do fotográfico ao virtual, operam com essas imagens e que tipos de implicações comunicacionais promovem.
\end{abstract}

Palavras-Chave: Fotojornalismo; fotografia documental; imagens de informação; relações interacionais.

\section{INTRODUÇÃO}

Embora se discuta a crise do papel da imagem documental, em face da exposição cada vez mais freqüente dos processos que envolvem suas manipulações, assim como de sua expansão ao mercado de usuários leigos que se constituem em jornalistas ou autores potenciais dos grandes veículos informativos, ela se manifesta com vigor no nosso universo de conhecimento, sobretudo aquele vinculado aos meios massivos de comunicação. As fotografias impressas e as imagens videográficas, televisivas ou da esfera virtual, se inscrevem como testemunhos dos fatos 
e têm sido tomadas como fontes de opiniões importantes para nossa visão de mundo. Elas tanto são utilizadas no meio acadêmico-científico, quanto no vasto domínio das diversas mídias, nas quais operam como provas testemunhais, orientações críticas, homologações estabilizadas de formas de ver o "real" ou desencadeadoras de efeitos afetivo-passionais nas relações intersubjetivas. Mesmo diante da multitude de exercícios experimentais voltados à desestabilização figurativa da imagem, e portanto de seu pretenso valor de referente, prevalecentes nas artes, ainda é forte a sua inserção em propostas de cunho informativo.

Em todos esses usos, a criação da imagem marcada por um propósito claramente documental, seja autoral, ou massiva como vem sendo usada no universo da informação, inscreve-se, porém, numa tensão recorrente entre caracterizar-se como representação de algo ou construção de um ponto de vista subjetivo. Dessa escolha decorrem ainda modalidades relacionais diversas, amparadas na mediatez ou imediatez dos atos apreensivos; num sistema de valores condicionantes do ato comunicativo que coloque em evidência as funções prática, cognitiva, afetiva ou fiduciária (calcada em supostos regimes de crença) das mediações simbólicas (FLOCH, 2002, págs. 183-226; 1986, págs. 11-33). A questão mais geral que norteia a presente proposta, então, é indagar como as diferentes mídias operam com essas imagens e que tipos de implicações comunicativas promovem.

A naturalidade com que são encaradas as imagens destinadas a representar fatos e pessoas reais determina o aplainamento de suas virtualidades significativas: à primeira vista, parecem todas conformes aos padrões discursivos vigentes no documentarismo visual de uma cultura, sobretudo pela aparência altamente figurativa e de suposta semelhança com aquilo a que se reportam. Na contramão dessa perspectiva, abordamos os discursos visuais em seus distintos regimes de interação, pelo simples fato de concebê-los como objetos significantes que, como tais, fazem parte de um sistema semiótico de que são apenas algumas das possíveis manifestações (GREIMAS, 2004, p. 84). Questionamos, assim, a assertiva bastante disseminada de que os processos icônicos, ou de alta concentração figurativa, se definem por traços de analogia com o objeto representado. Constituem, antes, formas culturalmente estabilizadas de "representação" do mundo e, na maior parte das vezes, politicamente hegemônicas de "mostrar a realidade tal como ela é", segundo os padrões estéticos considerados mais adequados de conformação com essa finalidade.

Guiando-se por tais princípios, concebemos, em suma, que os 
diferentes procedimentos destinados a criar efeitos de sentido (ou impressões) de realidade modelam as dinâmicas visuais, geram distintas expectativas e graus de cumplicidade entre os envolvidos no ato comunicativo, e acabam, por conseqüência, determinando os modos de apreensão da realidade por mediações simbólicas.

\section{Efeito de sentido de documentaridade}

Tomando como ponto de partida o pressuposto da semiótica discursiva (GREIMAS \& COURTÉS, 1979, verbetes referente/ référence/ referent, págs. 377-378; figurativização/ figurativisation/ figurativization, págs.185-188; iconicidade/ iconicité/ iconicity; 222223), consideramos as imagens informativas como um efeito de sentido de realidade, uma impressão resultante dos procedimentos discursivos, assentado sobre uma espécie de contrato tácito estabelecido entre os envolvidos no ato comunicativo, para quem o texto, verbal e não-verbal, assume o aspecto de um dizer verdadeiro ou, no mínimo, de um dizer que visa a "representar" os fatos reais. Nessa linha de pensamento, o mundo referencial é apreendido por crivos de leitura que o tornam significante, apresentando-se, ele também, como um texto suscetível de ser traduzido por meio de outras linguagens. As relações que se estabelecem, portanto, entre o que se chama realidade e linguagem constitui uma manifestação de tradução intersemiótica fundada em princípios culturais de representação. De acordo com esse quadro teórico, a imagem documental seria aquela que tem como finalidade, explícita ou não, testemunhar o fato ou evento simulado, construindose na base de dispositivos argumentativos ou afetivos que evocam os efeitos de semelhança e de presença. Se podemos falar em algum tipo de analogia nesse caso, trata-se de uma semelhança entre os traços das formas de expressão e os traços do conteúdo atribuídos à nossa leitura socializada do mundo, e não entre linguagem e realidade.

Nesse processo de figuração das experiências com o real, os discursos visuais podem assumir feições mais estabilizadas numa dada cultura, quando os procedimentos iconizantes convocam expedientes tradicionalmente estabelecidos de representação, ou, ao contrário, operar rupturas passíveis de se inscreverem em diferentes níveis de realização'.

Não se trata, portanto, aqui de definir o sentido de documental, pois parte-se do pressuposto de que esse aspecto se apresenta como resultado de estratégias, figurativo-enunciativas, tensivas e plásticas, de fazer crer - seja pelo pretenso traço de indicialidade (DUBOIS, 1993, p. 
61) postulado, seja pela sua ruptura, mobilizando, neste caso, o "fazer crer" ou o "parecer verdadeiro" justamente pelo questionamento de uma verdade ou realidade absoluta. Para este trabalho será considerada, então, como documental a imagem que se colocar como tal, o que engloba uma porção bastante ampla de nossas experiências com o mundo por intermédio de figuras, consideradas como informativas, científicas e artísticas, e manifestadas por um largo espectro de canais e suportes. Um recorte específico se faz, por conseguinte, necessário: estão excluídas da presente discussão, de partida, toda a gama de imagens vinculadas ao domínio científico, assim como as artísticas que visam a romper, por formas diversas de experimentalismo, qualquer tipo de ancoragem com eventos sociais, políticos e econômicos das sociedades. Enquadram-se em nossas reflexões as imagens do fotojornalismo e as chamadas fotografias documentais, presentes em revistas e jornais, do lado do impresso; os documentários videográficos, sobretudo de divulgação em programas massivos da televisão ou com inserções em telejornais com o fito de servirem de testemunho das notícias, do lado televisual; e blogs e sites de notícias, de base fotográfica ou ilustrados por imagens com várias relações de complementaridade entre o verbal e não-verbal. Com base nesse universo de manifestações é que pretendemos tecer a presente discussão visando a abordar as dinâmicas visuais constituidoras e constitutivas de nosso imaginário atual sobre o papel da imagem, em particular da fotografia, como referente das informações veiculadas pelas mídias.

Cada sociedade determina não só formas estabilizadas de representação visual da realidade, passíveis de serem axiologizadas positiva ou negativamente, seja por aquilo que representam ou constroem (fotografias que exaltam ou ridicularizam certos políticos, por exemplo, como aquelas projetadas na esteira das imagens oficiais ou nos "flagrantes delitos"2), seja pela sua própria compleição (fotos consideradas bem feitas ou de mau gosto), como também normatizam padrões tecnoestéticos que se consagram como hegemônicos numa dada cultura. Tais dispositivos servem para qualificar e legitimar o valor documental dos discursos, chancelados pelo "selo do padrão de qualidade", como se autooutorga a maior emissora televisiva brasileira, a Rede Globo de televisão, impondo-se como porta-voz de grande parte da sociedade brasileira. $\mathrm{Na}$ esteira desses padrões televisivos, em primeiro lugar, os jornais impressos também se modificam. O jornal impresso de maior circulação - Folha de São Paulo - vem renovando sistematicamente seu aspecto visual recorrendo cada vez mais a grandes imagens e a estratégias de 
notícias rápidas (V. Folha Corrida), e as revistas semanais, como a Veja, por exemplo, ampliam e multiplicam essas fotografias em ilustração estetizante, como a aprofundar a documentação das principais notícias da semana. Os jornais on-line não alteraram substancialmente esse quadro, e afirmam sua especificidade mais pela agilidade e ubiqüidade das informações do que pela potencialização de uma linguagem própria. Uma diferença significativa se inscreve em alguns sites e blogs de notícias, sobretudo aqueles exclusivos de fotografias, que retomam a diferença já convencional entre o fotojornalismo, de aspecto apressado, com recursos técnicos empobrecidos, e a fotografia documental, cujo traço marcante está no efeito enunciativo de presença do sujeito na construção simbólica.

Obviamente, os padrões técnicos têm condicionantes de ordem financeira e determinam, por sua vez, muitas das possibilidades de escolhas estéticas, como historicamente se viu com a inserção da cor nas fotografias, a apreensão de imagens únicas (o instante decisivo de (artier-Bresson ${ }^{3}$ ), a associação de imagem, som e movimento com efeitos de realidade, a qualidade de resolução e alcance do veículo, com variedade de ofertas a um público diferenciado, o que permite a uma mídia (principalmente a televisiva) agir com programas mais populares e mais experimentais, entre outras. No entanto, uma vez instalados como padrões estéticos, tais dispositivos podem servir de parâmetros e, ao mesmo tempo, de barreiras de entrada de outras produções no mercado, como afirma Bolaño (2000, págs. 234-235). Mais uma vez, o estilo de produção da Globo, que se autoproclama "padrão de qualidade", é exemplar a esse respeito. Entrar em concorrência com suas programações significa, de partida, aderir a uma estrutura discursivoestética que lhe é própria. Tal fato pode ser observado nos telejornais ou nos programas documentários das emissoras, mas também nos circuitos impressos, entre uma produção fotojornalística emanada das agências de imagens e aquela gerada pelos fotógrafos de uma agência independente como a Magnum, por exemplo. O mesmo parece ocorrer no universo dos blogs e sites (e toda ordem de novidades para as redes sociais e de compartilhamento de imagens que vão surgindo nessa esteira como os twitters, o flickr, etc.), evidenciando uma tensão freqüente da imagem de informação num eixo contínuo de produções hegemônicas (sendo a fama de muitas tributária de modismos tecnológicos) e contra-hegemônicas.

\section{Padrões discursivos e relações interacionais}

As evocações propiciadas pelas imagens, e que agem sobre 
os destinatários como instruções de leitura para a apreensão dos acontecimentos discursivos, são regidas, grosso modo, por duas formas de relações (FONTANILLE, 2005, págs. 142-148): aquelas assentadas na imediatez ou mediatez dos processos compreensivos. Da perspectiva de suas naturezas, a imediatez pode ser de ordem cognitiva (e prática), ou afetiva, assim como a mediatez pode ter dominância crítica ou simbólica (Id., págs. 142-145).

Examinando emissões televisivas de telerrealidade, Fontanille associa a imediatez cognitiva e prática às evocações centradas no conteúdo dos programas; a afetiva ao regime de crença estabelecido; a mediação crítica à ênfase no conceito subjacente a tal ou tal tipo de programa e a simbólica, pelo caráter de fidúcia que comporta, ao papel do animador. Incorporamos parcialmente algumas dessas dimensões para o estudo em questão, por nos parecerem úteis para a presente discussão. Em primeiro lugar, a tensão (e não simplesmente a oposição) entre mediatez e imediatez pode se revelar profícua, porque implica tanto um tempo de produção quanto de apreensão diferenciado: as imagens fotojornalísticas em geral, por exemplo, devem ser realizadas no "calor da hora" (quando não retiradas de arquivo para coberturas eventuais de matérias) e têm sua leitura determinada pela legenda. A fotografia documental de cunho autoral pressupõe a existência de um projeto e de sua execução, do mesmo modo que uma recepção mais contemplativa e demorada, sobretudo porque acaba se integrando ao universo das exposições, dos livros, catálogos, concursos de premiações, etc.

O fator "tempo" inscreve-se, dessa maneira, como um diferencial importante entre as duas, abrangendo todo o processo ligado ao ato fotográfico: o da captura, organização, edição e o da apreciação. No fotojornalismo, a agenda impõe um ritmo acelerado; na fotografia autoral, a sua desaceleração. Obviamente, a questão financeira, e todas as vantagens e desvantagens dais decorrentes, é condicionante dessa premissa.

Em suma, a valência relacional da mediatez/imediatez sobredetermina os modos de apreensão dos discursos visuais, que podem, em conseqüência, assumir valores axiológicos em eco ao modelo dos valores de comunicação e de consumo ( $v$. FLOCH, a respeito do marketing e da publicidade, bem como da fotografia, respectivamente 2002 e 1986; FONTANILLE, 2005, p. 145): práticos, lúdicos, críticos e simbólicos. Para a análise desses valores, é pertinente a apropriação das dimensões sistematizadas por Fontanille para o estudo das seqüências genéricas das aberturas de emissões televisivas (evocação do conteúdo, do conceito, 
do regime de crença e do papel do animador), as quais se encontram, por sua vez, determinadas também pelas valências modais do 1) saber fazer, em emissões destinadas a orientar atividades da esfera prática; 2) do crer, naquelas amparadas no fazer sentir dos regimes de crença; 3) do meta-saber em seqüências de abertura reveladoras do conceito de um programa, de sua função crítica e 4) do crer e do sentir nas evocações do papel do animador, em que este expressa a representatividade do programa, seu conteúdo e ideologia, colocando em destaque os valores simbólicos postulados por Floch e sustentando as relações intersubjetivas sobre laços afetivo-fiduciários.

Importando essas categorias ao exame das imagens fotográficas, é possível postular que a evocação pelo conteúdo põe em evidência a carga informativa de uma imagem. Consiste não apenas no exercício de um saber fazer, atinente à competência de poder mostrar aquilo de que se fala em jornalismo, como também de um fazer saber, de caráter transmissivo, homologando a imagem tradicional do jornalista de sujeito que sabe e faz veicular a informação, assim como de uma visão linear do processo comunicacional. Seu exemplo mais evidente é o do jornalismo diário, seja impresso, televisivo ou virtual. A retórica que o acompanha é a da certeza, do presente remissivo, das evidências testemunhais, fortalecidas por imagens ou delegações de vozes, tais como entrevistas, depoimentos, fontes de referência. A imagem, nesse caso, requer do leitor um exercício de mero reconhecimento e, eventualmente, de conexões interpretativas ${ }^{4}$.

A evocação pelo conceito pressupõe uma mediação cognitiva. Não se trata de gerar conteúdos imediatamente depreensíveis por lexicalizações ou figuras reconhecíveis, mas de traçar um perfil, uma proposta e o papel de um ato de linguagem. Segundo Fontanille, "a evocação do conceito instala uma distância técnica entre o espectador e a emissão a qual ele assiste, e também entre as regras de um artefato que se afirma como tal, sem consideração à relação com a realidade, nem mesmo com os investimentos simbólicos que poderiam comportar o conteúdo da emissão" (p. 143). Pode-se dizer que, no tocante à imagem, trata-se de discursos voltados para a sua própria consecução e aos efeitos que os dispositivos acionados para tal provocam na percepção do espectador, inscrevendo-o numa posição crítica em relação aos atos enunciativos em jogo. Instaura-se um sistema de avaliação que coloca em questão o gênero, os pontos de vista, assim como os vínculos intersubjetivos convocados. Seu exame deve passar necessariamente pela abordagem dos processos de construção figurativa, calcados em formas de 
estabilização e desestabilização das formas visuais. Assim, há vários dispositivos de caráter técnico-estético a diferenciar o fotojornalismo e a fotografia autoral, que vão desde a escolha dos equipamentos, modos e formas de circulação, a opção por uso ou não de filme, de flash, filtros, e até mesmo a definição por cores ou $\mathrm{p} / \mathrm{b}$. Deixemos de lado, por enquanto, essa dimensão. Convém, no entanto, ressalvar, que seria ingênuo a priori estabelecer conformidades entre tais escolhas e o caráter estético ou não das imagens; revelam-se hegemonias é claro, mas cada discurso institui a singularidade das composições. Além disso, as opções técnicas acabaram assumindo as caracterizações dos gêneros em que se inscrevem apenas como estilos hegemônicos.

A ser fiel com o modelo proposto por Fontanille, restam ainda duas dimensões para serem comentadas: a evocação pelo regime de crença e pelo papel do animador, que nos interessam particularmente neste ensaio. O papel do animador equivale no jornalismo, assim como nos discursos em sua totalidade, aos vários tipos de presença e participação do enunciador (o animador sendo considerado apenas como uma das múltiplas actorializações do enunciador) e das vozes por ele delegadas. A evocação pelo regime de crença envolve não só o grau de adesão fiduciária do leitor/espectador com respeito ao enunciado visual apresentado, como do compartilhamento afetivo com o discurso, e por meio dele entre os envolvidos no ato comunicativo, que predispõe a uma imediatez do sentir comum. Conforme esclarecido acima, não se pode delimitar rigorosamente os espaços de evocação dessas dimensões, mas evidenciar dominâncias, cientes de que os veículos se contaminam e os discursos assumem várias feições, pela força da própria concorrência, o que justifica programas televisivos, assim como produtos fotojornalísticos, dissonantes na massa uniforme das grandes produções cotidianas. A partir de observações empíricas nada exaustivas, e de estudos já efetivados por outros autores, seria plausível associar o predomínio da evocação pelo conteúdo às fotografias do jornalismo diário e a evocação do conceito à fotografia de reportagem, de marca autoral (e suas reproduções em programas televisivos ou nos processos de comunicação informativa virtuais), o que implicaria do ponto de vista relacional, respectivamente, imediatez cognitiva de um lado e mediação crítica de outro. Essa afirmação deve ser considerada, porém, com cautela, uma vez que a própria fotografia enquanto projeto documental está sujeita a determinações de diversas ordens, constituindo-se os padrões tecno-estéticos adotados como uma formalização visual do próprio modo de encarar as linguagens: sejam como mediações, sejam 
como experiências integradas à totalidade da realidade.

\section{Tensões afetivo-cognitivas e derivações intersubjetivas}

As tensões possíveis de ocorrerem entre os eixos da imediatez/ mediatez e cognitivo/afetivo mostram-se adequadas para compreender um outro tipo de tensão, normalmente associada à divergência mais ampla da fotografia de imprensa e da fotografia documental, e que se concretiza no debate tradicional sobre os distintos graus de valorização atribuídos à chamada foto-choque e a fotografia autoral de caráter documental. Os comentários tecidos sobre o terreno limítrofe, mas em geral fluido, entre esses dois produtos costumam ser vagos. Dizem mais da subjetividade do receptor, no sentido de que expressam expectativas ou sensações despertadas diante de uma imagem, do que de suas potencialidades de leitura. Para Barthes (2006, p. 107), por exemplo, o incômodo da foto-choque reside no fato de que tudo está dito (ou mostrado) no discurso; o fotógrafo não deixa brechas para a imaginação do enunciatário, que tem diante de si todas as indicações de leitura e de sensações, expostas da forma mais gritante possível. Jean Baudrillard, por seu lado, em entrevista concedida ao jornal Le Monde, em The International Photojournalism Festival of Perpignan - Visa pour I"Image, na França, evento máximo de premiações das fotografias de imprensa, critica a estetização artificial das imagens, e postula a necessidade de maior presença de espaços vazios nas fotos (vazio, aqui, pode ser concebido nas duas acepções: físico, de um redimensionamento do uso do espaço na composição do discurso visual, e simbólica, de uma maior evocação de suas virtualidades semânticas e sensíveis, o que reitera em certa medida a afirmação recorrente de que o sentido deve ser evocativo e não representativo).

O impacto (quando o há) suscitado pela foto-choque tem afinidade com atitudes reativas, despertadas pelo espanto, nojo, medo, repulsa, diante de figurações que a cultura, em determinados momentos de sua história, prescreveu como não representáveis, portanto contrárias aos padrões de conveniência ética e moral do que pode ser visto ou do que pode se dar a ver 5 . A sua emergência e proliferação no seio das mesmas sociedades anuncia uma transformação cultural, indicadora do enfraquecimento dos valores anteriores. Se tais imagens perdem, porém, o vigor de seus efeitos, não eliminam totalmente a força de atuação sobre os estados patêmicos, seja pelo apelo à curiosidade mórbida, que alimenta a produção de múltiplos discursos sensacionalistas da atualidade, seja pela sua recusa em manifestos indignados diante de sua 
própria exposição. Reveladoras da crueldade humana, ou do impacto das tragédias sobre nossa limitada condição, as imagens-choque expõem corpos mutilados, sangue, crianças mortas, todos ingredientes eficazes para o estímulo às relações emotivas.

A atenção se volta nesse caso, entretanto, para o terror da própria imagem, daquilo que ela comporta para o processo de "reconhecimento" visual, rapidamente apreensível de uma fatia da realidade (antes mesmo que se tenha tempo de fechar os olhos para não vê-la). Sua ação está centrada na imediatez cognitiva e afetiva. Nesse sentido, pode vir a ser avaliada como "invasiva", uma vez que implica uma ação direta, impositiva da imagem sobre o corpo próprio, sem o movimento de disponibilidade afetiva do sujeito necessário ao encontro estético, do qual resulta a sua transformação no mundo. Se chega a nos permitir uma reflexividade crítica sobre o fato, ela ocorre posteriormente graças a sua vinculação a uma informação suplementar, à qual adere como se fosse contígua ao real, gerando, por conseguinte, o efeito ilusório de um sentido de realidade e de verdade. Daí que sua incidência em doses freqüentes, pela previsibilidade do choque, atenua o impacto e suscita a banalização do ato discursivo. A mesma rapidez com que se opera o fenômeno da apreensão pode ser observado na efemeridade de duração do impacto, passível de ser reduzido a zero pela exaustividade da ocorrência.

Esses casos-limites são significativos para dimensionar a diferença entre uma imagem capaz de promover atos compreensivos (apreender junto), pela ação do sensível, e a que tem no emotivo mais vulgarizado, ou mais banalizado, calcado no princípio do reconhecimento imediato do referente representado, pois ele é condição necessária da precipitação do efeito impactante, o dispositivo eficaz das relações intersubjetivas. Podemos dizer que, neste último caso, a imediatez cognitiva e a afetiva estão intimamente relacionadas para promover vínculos passionais, que não são obrigatoriamente estabelecidos sobre regimes de crença ou pelo papel do enunciador, mas pela ação direta de mediação das imagens.

Por outro lado, embora também privilegiando as evocações de conteúdo e afetivas das imagens, a esfera informativa do virtual tem atribuído um importante papel ao enunciador, não mais como competência restrita do jornalista, sobretudo quando se considera o incremento das formas colaborativas que o jornalismo vem assumindo nesse domínio. A questão é saber até que ponto essa descentralização de um papel, para afirmá-lo positivamente como condição de igualdade discursiva, é determinante de uma nova postura crítica das imagens que circulam nas mídias em geral. 


\section{No universo do jornalismo participativo: o papel do enunciador}

As sistemáticas de criação, circulação e troca de informações na rede alteram profundamente essa posição centralizadora do jornalismo como sujeito competente para o fazer-saber, sobretudo com a instituição dos Centros de Mídias Independentes, os softwares livres, o jornalismo de pauta aberta. Embora desestabilizadora no sentido das interações obtidas, essa nova condição não parece ter alterado de maneira significativa a produção das imagens que acompanham as matérias verbais. Em outros termos, elas continuam, em seu uso mais freqüente, servindo de ancoragem aos textos, com forte predomínio, por limitações tecnológicas, aos recursos dos thumbnails, pequenas fotos que se justapõem às chamadas, ao contrário do que acontece no jornalismo impresso e televisivo, em que predominam as grandes e impactantes imagens (de alta definição e resolução, "como se fossem reais"). Há, obviamente, o recurso dos links específicos de imagens, das galerias de fotos, que propiciam a extensão do olhar sobre outras da mesma série ou de outras séries. Um olhar em abismo tensionado entre reconhecer a prova do que se relata e perder-se no leque de imagens que conduzem a novas figuras, que levam, por sua vez, a outros assuntos em estrutura labiríntica. Tal arquitetura nem sempre é reveladora de descobertas, nem sempre proporcionadora de um pensamento hermenêutico, pois a repetição do mesmo, sobretudo quando ocorrem fatos de repercussão mundial, faz com que o caráter circular da informação logo se efetive e os sentidos se esvaziem.

Nas formas do jornalismo participativo, de pauta aberta, cada vez mais a evocação pelo conteúdo e o papel do enunciador prevalecem. Podese dizer que são eles a determinar os regimes de crença nas relações intersubjetivas, mas não como fontes especializadas ou representantes de veículos de influência, tal como nos moldes tradicionais. Na rede, os sujeitos expõem a sua participação nos fatos, mostram o que falam pela relação de presença que tiveram com os acontecimentos no calor da hora. Pouco importa, a princípio, a elaboração estética de uma imagem com vistas seja a funcionar como stopper, no estilo mais publicitário possível, seja como indutora de uma contemplação reflexiva. O momento está ali condensado, em toda a sua imperfeição e a assinalar, com isso, não só a simultaneidade da tomada, mas também a impotência humana. Disso decorre seu valor de verdade. Mesmo motivando polêmicas acaloradas sobre a veracidade de uma imagem, é o papel do enunciador, enquanto sujeito participante do fato e não reflexivo sobre o fato, que está em jogo. Nisso reside o paradoxo de nossa situação atual: o desmantelamento 
do valor referencial do jornalismo informativo proporcionado pela rede se neutraliza na própria condição da mesma de retomar, como fênix renascida, o papel da imagem para a documentação do real. Estar em ato, representar em situação, fazer circular em tempo real, mostrar-se como testemunha e participante, eis aí os ingredientes essenciais de uma documentaridade amparada na velha fórmula do contador de histórias, tal qual a lenda do índio Timbira que relata os feitos em I-Juca-Pirama de Gonçalves Dias: "Meninos, eu vi! ${ }^{6}$

\section{NOTAS}

1 Cabe aqui lembrar as afirmações recorrentes de que a figuratividade dominante nas sociedades ocidentais está amparada no perspectivismo renascentista, ou seja nos dispositivos de passagem das estruturas tridimensionais para as superfícies bidimensionais, em que a noção de profundidade passa a ser representada, a partir de certos recursos codificados, como efeito de sentido. No que concerne à fotografia, as reflexões de Vilém Flusser (2003) sobre o caráter conceitual do aparelho (assentado sobre essa visão perspectivista) na elaboração da imagem, têm sido debatidas (MACHADO, 1997, págs. 220-235, COUCHOT, 1993, págs. 37-48), sobretudo quando se trata de considerar as possíveis desestabilizações provocadas pelos dispositivos técnicos que as sucederam, como no caso do cinema, da tv, do vídeo e do computador.

2 V. Landowski, 2004, págs. 31-70.

3 V. Cartier-Bresson, In: Fontcuberta, J., 2003, págs. 221-236.

4 De outro lado, na esfera acadêmica de estudo das imagens, muitos trabalhos teóricos de análise semiótica ainda se dedicam a investigar a imagem, mesmo em suas diversas nuanças de apresentação e construção de intersubjetividades, sob esse ponto de vista descritivo ou interpretativo, aplainando igualmente a complexidade do fenômeno. Dito em outros termos, confundem a análise com um mero exercício de reconhecimento e interpretação de conteúdos, do que decorre, com justeza, a impressão dos que a olham a distância, e com reservas. Além disso, mesmo em algumas abordagens pretensamente mais rigorosas, ocorre, pelo menos no que toca à semiótica de origem estrutural, o fato, como diz Landowski, 
de "projetar sobre qualquer objeto de estudo justamente o tipo de grade de leitura que era a regra, há mais de cinqüenta anos, entre os fundadores da abordagem estrutural" (2008, p. 50-51), do que decorre, do mesmo modo, um tipo de crítica que a questiona genericamente apenas nestes termos, como se se falasse dos seus estados mais atuais.

5 Ver, a esse respeito, o excelente estudo de Vivian Sobchack, publicado em Inscribing ethical space: tem propositions on death, representation, and a documentary. Quartely Review of film studies. Vol. 9, nº 4, 1984.

6 Gonçalves Dias. Antologia Poética. 5a edição. Rio de Janeiro: Agir, 1969. Acessado em http://www.cce.ufsc.br/ nupill/literatura/i-jucapirama.html

\section{REFERÊNCIAS BIBLIOGRÁFICAS}

BARTHES, R. Mitologias. São Paulo: Difel, 2006.

BOLAÑO, C. Indústria cultural, informação e capitalismo. São Paulo: Hucitec/ Polis, 2000.

CARTIER-BRESSON, H. El instante decisivo (1952). In: FONTCUBERTA, J.(ed.). Estética fotográfica. Barcelona: Gustavo Gili, 2003, págs. 221236.

COUCHOT, E. Da representação à simulação: evolução das técnicas e das artes da figuração. In: PARENTE, A. (org.) Imagem-máquina: a era das tecnologias do virtual. Rio de Janeiro, Ed. 34, 1993, pp.37-48.

DUBOIS, J. O ato fotográfico e outros ensaios. Campinas, SP: Papirus, 1993.

FLOCH, J.-M. Les formes de I'empreinte: Brandt, Cartier-Bresson, Doisneau, Stieglitz, Strand. Périgueux, Pierre Fanlac, 1986.

FLOCH,J.M. Sémiotique, marketing et communication: sous les signes, les stratégies. Paris: PUF, 2002.

FLUSSER, V. A filosofia da caixa preta: ensaios para uma futura filosofia da 
fotografia. Rio de Janeiro: Relume Dumará, 2002.

FONTANILLE, J. Seqüência genérica das emissões de televisão: promessas, evocações e dinâmicas visuais. In: Significação e visualidade: exercícios práticos. Porto Alegre: Sulina, 2005, págs. 123-159.

GREIMAS, A.-J. Semiótica figurativa e semiótica plástica. In: OLIVEIRA, A.C. de (Org.). Semiótica plástica. São Paulo: Hacker Editores, 2004.

GREIMAS, A. J. \& COURTÉS, J. Dicionário de semiótica. São Paulo: Cultrix, 1979.

LANDOWSKI, E. A sociedade refletida. São Paulo: EDUC/Pontes, 1992.

- Flagrantes delitos e retratos. Galáxia: revista transdisciplinar de comunicação, semiótica, cultura. Programa Pós-Graduado em Comunicação e Semiótica da PUC-SP. São Paulo: EDUC; Brasília: CNPq, nº 8 , out. 2004, págs. 31-70.

. Da interação, entre Comunicação e Semiótica. In: PRIMO, A. et al. Comunicação e Interações. Livro da COMPÓS 2008. Porto Alegre: Sulina, 2008, págs. 43-70.

LEDO, M. Documentalismo fotográfico. Éxodos e identidad. Madrid: Catedra, 1998.

MACHADO, A. As imagens técnicas: da fotografia à síntese numérica. Précinemas \& pós-cinemas. Campinas,SP: Papirus, 1997, págs. 220-235.

SOBCHACK, V. Inscribing ethical space: tem propositions on death, representation, and documentary. Quartely Review of film studies. Vol. 9, nº 4, 1984 (Tradução de Silvana Vieira). [cópia xerografada]

Kati Caetano é professora do Mestrado em Comunicação e Linguagens, Universidade Tuiuti do Paraná, Curitiba, Doutora em Letras pela Universidade de São Paulo-USP, com Pós-Doutorado em Semiótica (199394) e Ciências da Linguagem (2002-2003) na França. der do grupo de Pesquisa Usos e Interfaces da Imagem nas Mídias/UTP/PR/Brasil. E-mail: katicaetano@hotmail.com 